\title{
The functional morphology of the branchial chambers and associated structures of Ebalia tuberosa (Crustacea : Decapoda : Leucosiidae), with special reference to ventilation of the egg-mass
}

\author{
PATRICK J. SCHEMBri* \\ University Marine Biological Station, Millport, \\ Isle of Cumbrae, Scotland
}

(Accepted 10 March 1981)

(With 9 figures in the text)

\begin{abstract}
Ebalia tuberosa bury themselves in sediment but do not construct permanent burrows. There are no functional Milne-Edwards' openings, the respiratory currents passing along channels formed by apposition of several interlocking buccal appendages. In adult females, the dome-like abdomen fits over the concave sternum to form a large abdominosternal chamber which completely encloses the egg-mass. The branchial chambers are connected to the abdominosternal chamber by two branchiosternal canals plugged by modified pericardial sacs which act as one-way valves. When the telson is extended, water is sucked into the abdominosternal chamber and then into the branchial chambers, thus ventilating the eggmass. The setation of the respiratory and associated structures serves to lock appendages together, to form screens and gaskets and to groom the buccal appendages. Setal morphology is shown to be correlated with function.
\end{abstract}

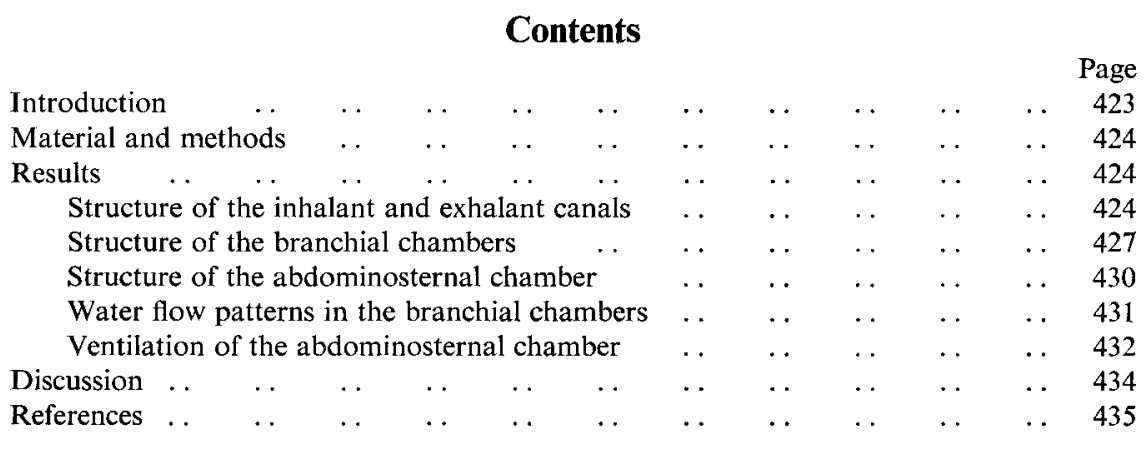

\section{Introduction}

Except when foraging for food, Ebalia tuberosa (Pennant) spends most of its time buried in the muddy gravel on which it lives (Schembri, 1980). In common with other decapods which bury themselves in soft substrata but do not construct permanent burrows, $E$. tuberosa faces the problem of maintaining a flow of oxygenated water through the branchial chambers without clogging the gills with sediment. As in other leucosiids, this problem is solved by having a pair of inhalant channels, formed partly by the buccal frame and partly by some of the buccal appendages, which conduct water from the surface of the

* Present address: Portobello Marine Laboratory, P.O. Box 8, Portobello, New Zealand. 
sediment to the openings of the branchial chambers (Balss, 1940, 1957; Glaessner, 1969). No detailed study of the functional morphology of these structures or of that of the branchial chambers of any leucosiid has been made, however.

A second problem faced by burrowing crabs is how to keep the egg-mass from getting fouled by the sediment. In crabs of the genus Ebalia, the abdomen and sternum are modified to form a spacious chamber (the abdominosternal chamber) in which the egg-mass is completely enclosed. It is obvious that this is an adaptation for burrowing and serves to protect the eggs from fouling but, as observed by Balss (1940), the problem of ventilating the egg-mass still remains.

In this study the structure of the branchial and abdominosternal chambers and associated structures of $E$. tuberosa is related to their function and special attention is given to how the two above-mentioned problems are overcome.

\section{Material and methods}

Crabs were collected by dredging on muddy-gravel bottoms at depths of $40-50 \mathrm{~m}$ off Farland Point, Isle of Cumbrae, Scotland.

Specimens were narcotized in tap-water and killed and fixed in $70 \%$ ethanol. Gross morphology was studied by dissection of both untreated and decalcified specimens. Decalcification was carried out by leaving crabs in a $3 \%$ solution of concentrated nitric acid in $70 \%$ ethanol. Individual mouthparts were dissected out, stained overnight in a $1 \%$ solution of lignin pink and then examined under a stereomicroscope. For detailed examination of the setae, small pieces of the integument were splintered off and examined under a compound microscope using brightfield and phase-contrast optics. Setae and other structures were also examined using the SEM. For this, selected structures were dissected out, dehydrated in graded alcohols, air-dried in a desiccator and then mounted on aluminium stubs with Silver-Dag (Agar Aids Ltd), coated with gold-palladium and examined in a Cambridge 600 SEM.

The structure of the branchial and abdomjnosternal chambers was studied by making internal casts of wax using standard vacuum-embedding techniques. To study water currents and the patterns of water flow in the branchial chambers, the branchial chambers of living crabs were exposed by removing part of the overlying carapace. A thin sheet of "Perspex", moulded to the shape of the carapace, was then sealed over the opening with IS 12 cyanoacrylate adhesive after the technique of Hughes et al. (1969). Water currents were traced by pipetting a solution of Janus green stain in seawater in the inhalant stream.

Hydrostatic pressure changes in the branchial and abdominosternal chambers were studied using George Washington PT400 pressure transducers attached to $0.8 \mathrm{~mm}$ diameter cannulae implanted in the branchial and abdominosternal chambers of living crabs through holes drilled in the carapace and abdomen, respectively.

\section{Results}

In the following descriptions, the nomenclature of the various setal types follows the scheme proposed by Factor (1978).

\section{Structure of the inhalant and exhalant canals}

A brief description of the structure of the inhalant and exhalant canals of $E$. tuberosa has already been given (Schembri, 1979). 
The openings of the branchial chambers are situated at the bases of the $3 \mathrm{rd}$ maxillipeds (Fig. 1). The inhalant respiratory currents flow down to these openings through two inhalant canals, one on either side of the buccal frame. The dorsal wall of each inhalant canal is formed by a groove in the buccal frame running from immediately anterior to the tip of the exopodite of the 3rd maxilliped to the entrance of the branchial chamber. Proximally, the endopodite and exopodite of the 2nd maxilliped and the exopodite of the 3rd maxilliped slot together to form a gutter which fits over the groove in the buccal frame to form a closed tube. Distally, this gutter is formed by the exopodites of the 2nd and 3rd maxillipeds only (Fig. 1).

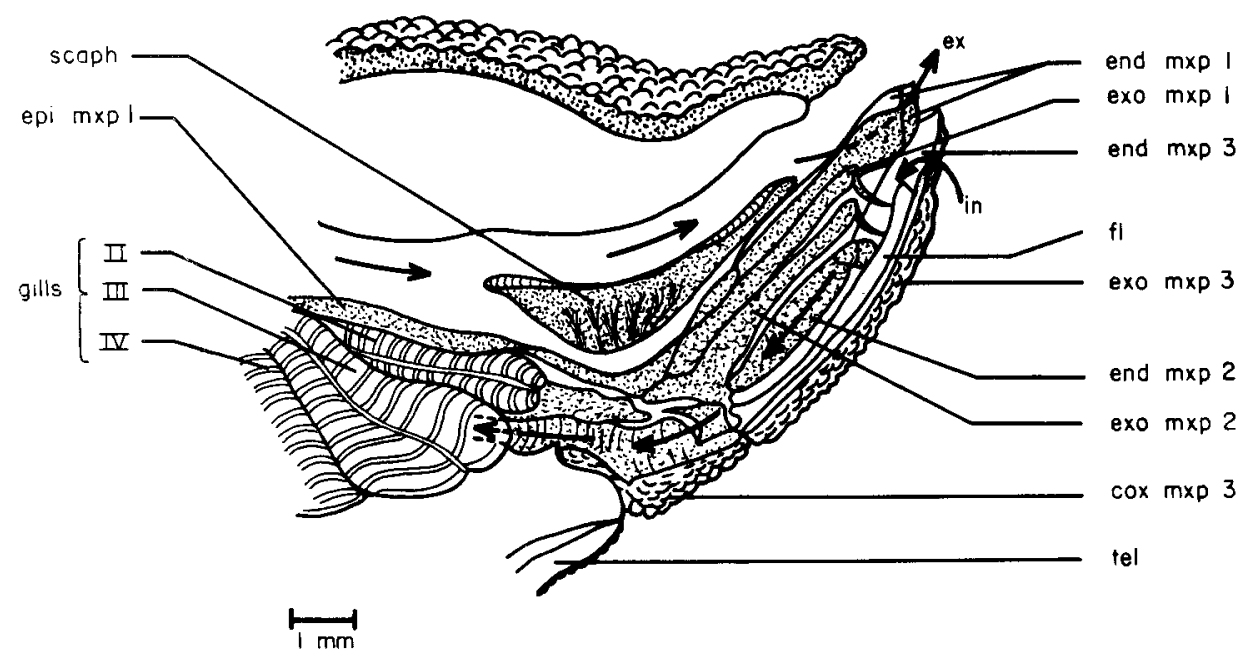

Fig. 1. Longitudinal section through the right inhalant canal and branchial chamber of E. tuberosa to show the arrangement of the mouthparts and the paths of the inhalant (in) and exhalant (ex) currents. Setae are not shown. Key: cox. mxp3, coxipodite of the 3rd maxilliped; end. mxp1, endopodite of the 1st maxilliped; end. mxp2, endopodite of the 2nd maxilliped; end. mxp3, endopodite of the 3rd maxilliped; epi. mxp1, epipodite of the 1st maxilliped; exo. mxp1, exopodite of the 1st maxilliped; exo mxp2, exopodite of the 2nd maxilliped; exo. mxp3, exopodite of the $3 \mathrm{rd}$ maxilliped; fl, flange on the internal surface of the exopodite of the 3 rd maxilliped; scaph, scaphognathite; tel, telson.

On the internal surface of the medial edge of the exopodites of the 3rd maxillipeds, there is a raised flange (Fig. 1) which bears rows of type F1 serrulate setae. These interlock with similar setae on the lateral edge of the endopodites and on the medial edge of the exopodites of the 2nd maxillipeds (Figs 4, 6(a)). The lateral edges of the exopodites and coxipodites of the 3rd maxillipeds are lined with type A plumose setae (Figs 5, 6(b)) which interlock with other setae of the same type lining the lateral edges of the buccal frame.

Proximal to the branchial chambers the exopodite and endopodite of each 1st maxilliped slot together and fit over the wall of the buccal frame to form the exhalant canals. Distally, these canals become confluent in a common exhalant chamber (Fig. 1). The walls of this chamber are formed by the expanded tips of the endopodites of the 1st maxillipeds, which lock together by means of flanges bearing rows of type B1 pappose setae and fit over the buccal frame (Fig. 3). The floor of the exhalant chamber is formed by the dorsal surface of the labrum. 
The 3rd maxillipeds (Fig. 5) function as opercula regulating the aperture of the inhalant and exhalant canals. When the crabs are disturbed, the 3rd maxillipeds are pressed backwards into the buccal frame efficiently sealing it and ventilation of the branchial chambers stops. The medial and lateral edges of the endopodites and the outer medial edges of the exopodites of the 3rd maxillipeds are lined with small type B1 pappose

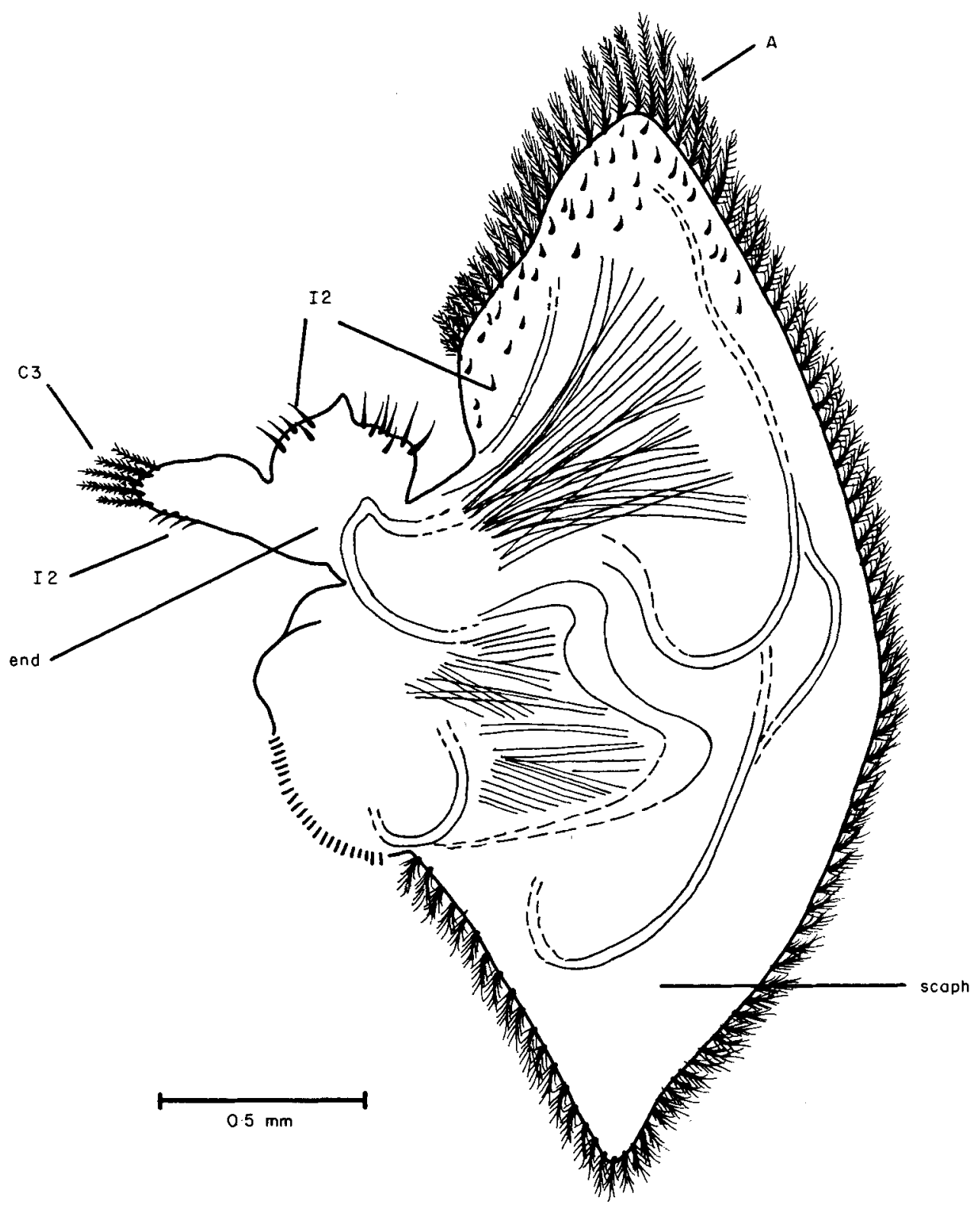

Fig. 2. E. tuberosa: left 2nd maxilla in external view. Key: end, endopodite; scaph, scaphognathite. Other symbols correspond to the setal nomenclature scheme of Factor (1978) (see text). 
setae (Figs 5, 6(c)) which lock these appendages together when the 3rd maxillipeds are retracted.

\section{Structure of the branchial chambers}

As in other brachyurans, the branchial chambers are bounded by the branchiostegites on the outside and by the body wall on the inside. Anteriorly, the branchial chambers narrow to become the pump chambers which house the scaphognathites. The two pump chambers form the obvious humps of the hepatic region of the carapace of E. tuberosa. The respiratory currents are generated by the beating of the scaphognathites in a manner similar to that described for other species of crabs (Atkinson, 1971; Scammell, 1971; Pilkington \& Simmers, 1973). E. tuberosa is unusual in that ventilation of the branchial chambers is not continuous but takes place in a characteristic intermittent manner (Schembri, 1979).

The edges of the scaphognathites are lined with a single row of type A plumose setae (Figs 2,6). This setal fringe touches the walls of the pump chamber and acts as a gasket. The floor of the pump chambers is formed by the expanded base of the epipodite of the 1st maxillipeds and, anteriorly, by the base of the 1st and 2nd maxillipeds (Fig. 1). The

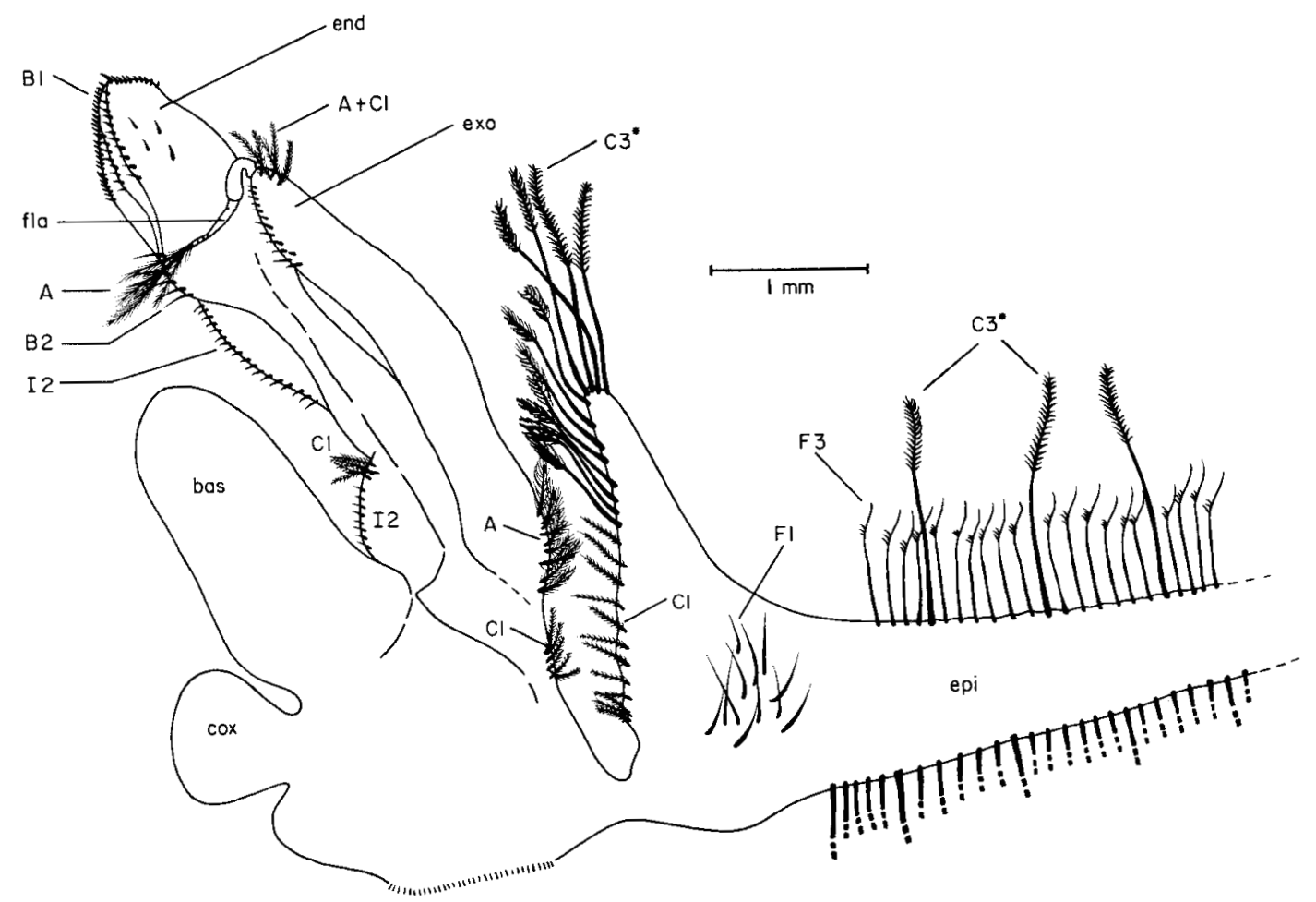

FIG. 3. E. tuberosa: left 1 st maxilliped in external view. For clarity, the basipodite and coxipodite are shown in outline only and only part of the epipodite and its setation is shown. Key: bas, basipodite; cox, coxipodite; end, endopodite; epi, epipodite; exo, exopodite; fla, flagellum. Other symbols correspond to the setal nomenclature scheme of Factor (1978) except for $\mathrm{F} 3$ and $\mathrm{C} 3{ }^{*}$ which are described in the text and represent serrulate and modified plumodenticulate setae, respectively. 
expanded base of the epipodite of the 1st maxilliped has an antero-laterally directed lobe which lies beneath the scaphognathite (Figs 1,3). This lobe bears a single row of modified type C3 plumodenticulate setae (see below) along its morphologically medial edge (Fig. 3). On the upper surface of the expanded base of the epipodite there is a small field of type F1 serrulate setae (Fig. 3). The function of these various setae is probably to clean the ventral surface of the scaphognathites and to preen their setal fringes.

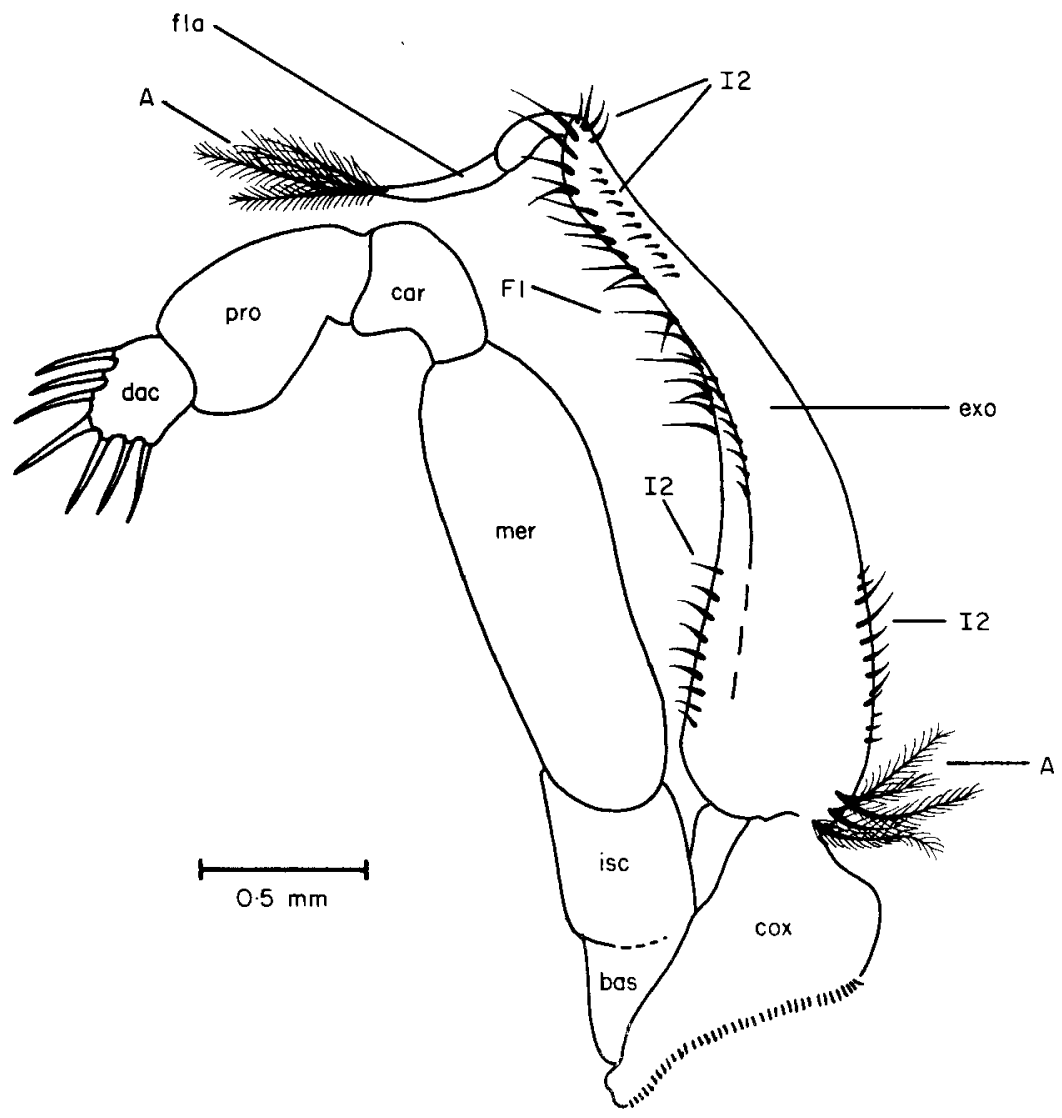

Frg. 4. E. tuberosa: left 2nd maxilliped in external view. For clarity, the endopodite is shown in outline only. Key: bas, basipodite; car, carpopodite; cox, coxipodite; dac, dactylopodite; exo, exopodite; fla, flagellum; isc, ischiopodite; mer, meropodite; pro, propodite. Other symbols correspond to the setal nomenclature scheme of Factor (1978).

E. tuberosa has six phyllobranchiate gills and two epipodites. The 1 st and 2 nd maxillipeds do not carry gills. The 3rd maxilliped carries two arthrobranchs (gills I and II), the 1st pereiopod carries another two arthrobranchs (gills III and IV), while the 2nd and 3rd pereiopods carry one pleurobranch each (gills V and VI, respectively). Only the Ist and 3rd maxillipeds carry epipodites. That carried by the 3 rd maxilliped has a rudimentary mastigobranch and is not functional (Fig. 5). The mastigobranch of the epipodite of the 1 st maxilliped is well developed and sweeps the outer surface of the gills. Both edges of the mastigobranch carry a row of very long setae of two types (Fig. 3). One type are 
modified $\mathrm{C} 3$ plumodenticulate setae in which the distal one third of the shaft has very long serrated setules arranged in an irregular manner (Fig. 6(d)). The other type has no exact counterpart in Factor's (1978) scheme and is here called F3. In setae of this type there are two rows of fine setules arranged at an angle of about $40^{\circ}$ to each other in the distal one-third of the shaft. Towards the tip, these setules are replaced by small peg-like denticulations (Fig. 6(e)). These two types of setae are present in unequal numbers along the mastigobranch, approximately every sixth seta being of the modified C3 plumodenticulate variety (Fig. 3).

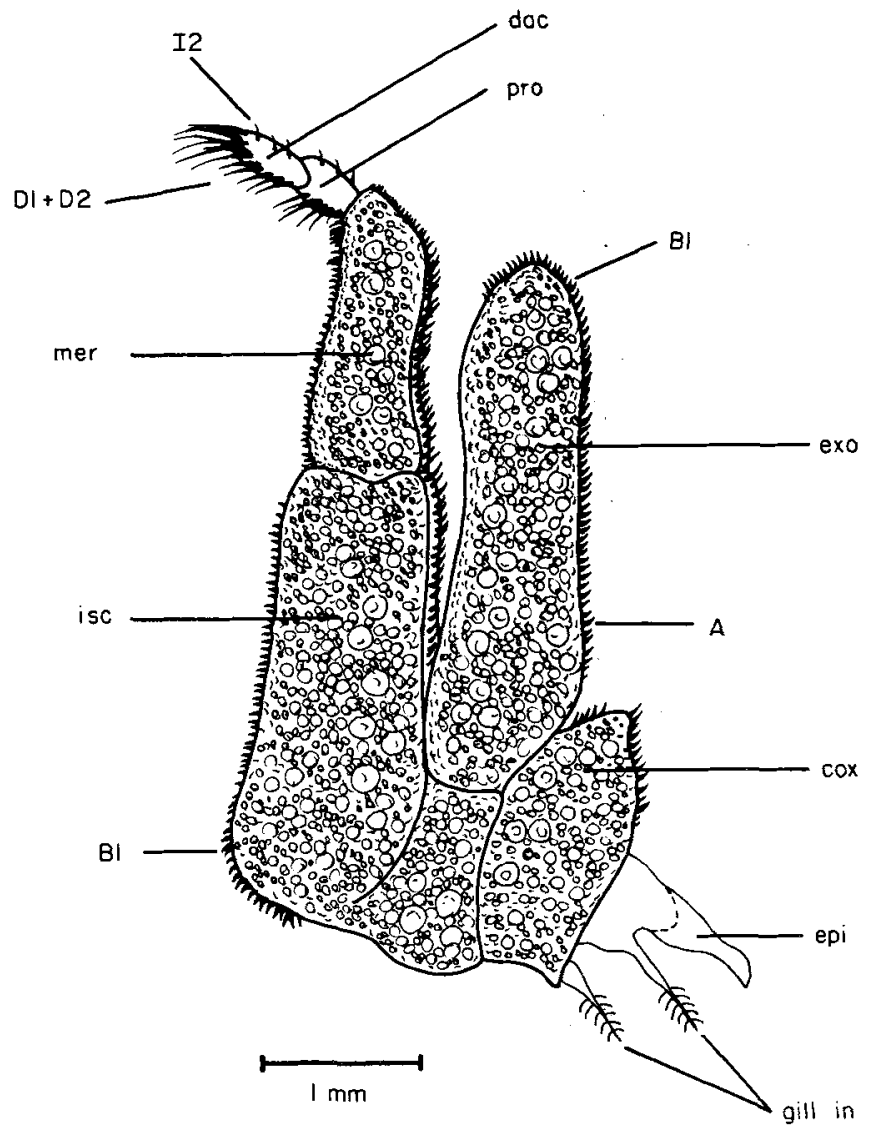

FIG. 5. E. tuberosa: left 3rd maxilliped in external view. Key: cox, coxipodite; dac, dactylopodite; epi, epipodite; exo, exopodite; gill. in, gill insertions; isc, ischiopodite; mer, meropodite; pro, propodite. Other symbols correspond to the setal nomenclature scheme of Factor (1978).

Gills III-VI are the largest and curve upwards, inwards and backwards to converge just beneath the roof of the branchial chamber at the level of the $3 \mathrm{rd}$ pereiopod. Gills I and II are smaller and lie more or less at right angles to the long axes of gills III-VI, resting on a narrow calcified shelf projecting from the dorso-lateral walls of the endopleurites of the thoracic somites. Beneath this shelf the lateral edges of the endopleurites have a gutter running antero-posteriorly which, in adult female crabs, reaches as far as the branchiosternal openings (Fig. 7) (see below). 
In adult female $E$. tuberosa, each hypobranchial chamber is connected to the abdominosternal chamber by a small canal (the branchiosternal canal). This is situated posteriorly in the floor of the branchial chamber just behind the last thoracic sternite and is bounded anteriorly by the posterior wall of the last thoracic somite and posteriorly, by the anterolateral edge of the 1st abdominal somite (Fig. 7). Each branchiosternal canal is plugged by a sac-like valve which is joined postero-medially to the body wall and which fits exactly in the canal. The free side of the valve consists of a convoluted membrane which folds up like a bellows when the valve hinges upwards. The posterior tip of the valve (i.e. that facing the abdominosternal chamber) is covered by a sclerotized cap (Fig. 7).

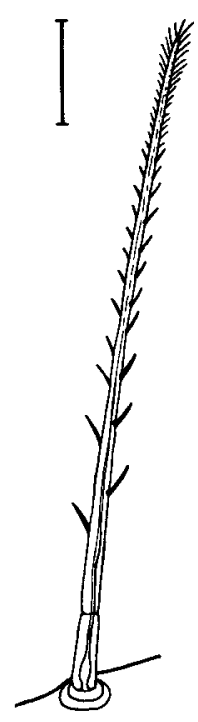

(a)

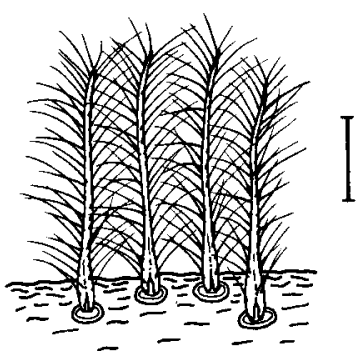

(b)

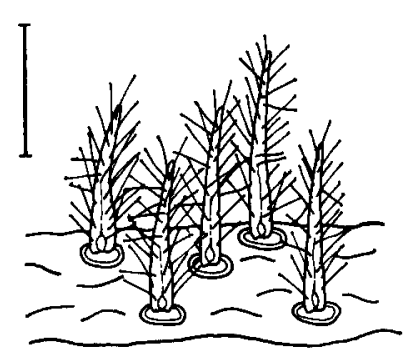

(c)

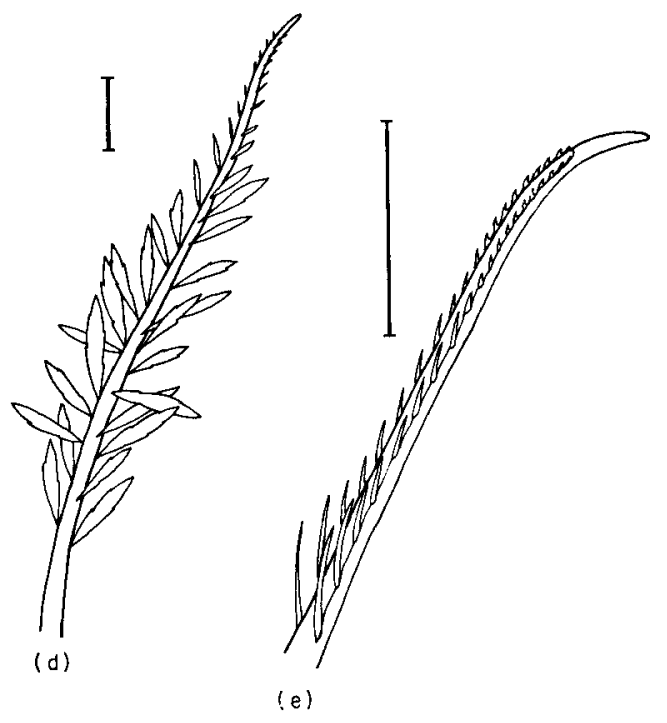

(e)

FIG. 6. Setae from the respiratory structures of E. tuberosa: (a) type F1 serrulate seta from the lateral edge of the meropodite of the endopodite of the 2nd maxilliped; (b) plumose setae from the lateral edge of the exopodite of the 3rd maxilliped; (c) type B1 pappose setae from the lateral edge of the 3rd maxilliped; (d) tip of a modified type C3 plumodenticulate seta from the mastigobranch of the epipodite of the 1st maxilliped; (e) tip of a type F3 serrulate seta from the mastigobranch of the epipodite of the 1st maxilliped. In all cases the scale bar represents $40 \mu \mathrm{m}$.

The valves are modified pericardial sacs and are covered by a thin cuticle which is an extension of that lining the branchial chambers. The lumen of the sacs is filled with a loose connective tissue containing muscle fibres and is confluent with the pericardial cavity. The pericardial sacs of $E$. tuberosa are histologically very similar to those of Maja, Carcinus (Cuénot, 1891), Xantho (Cuénot, 1893), Cancer (Pearson, 1908) and Gecarcinus (Bliss, 1963).

\section{Structure of the abdominosternal chamber}

In adult female $E$. tuberosa, the 3rd-6th abdominal segments are fused to form a domelike structure whose lateral edges are bevelled and which fits exactly onto the concave 
sternum forming the abdominosternal chamber. The telson is movable and takes the form of a flap which fits into an anterior notch in the sternum just beneath the point of articulation of the 3rd maxillipeds (Fig. 1). The free edges of the telson carry type A plumose setae which interlock with type B1 pappose setae on the postero-medial edges of the endopodites of the 3rd maxillipeds. The telson acts as a valve controlling the entry of water into the abdominosternal chamber. The bevelled edges of the abdomen and the sternum are also lined with type A plumose setae.

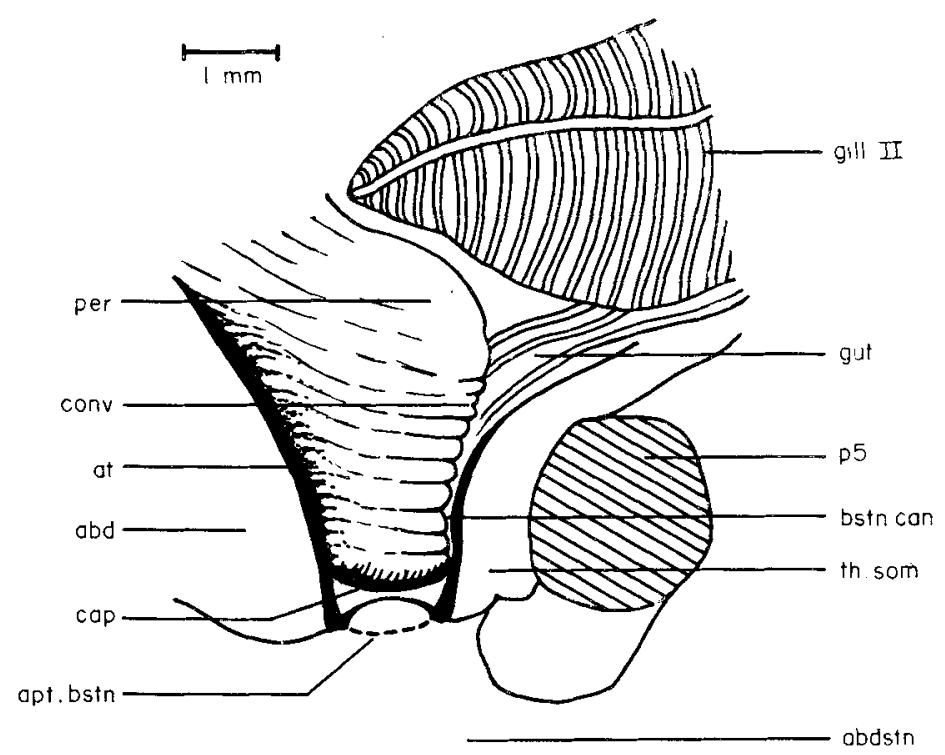

FIG. 7. Dissection of the posterior region of the right branchial chamber of an adult female E. tuberosa to show the branchiosternal canal and associated structures. Key: abdstn, abdominosternal chamber; abd, 1st abdominal somite; at, region of attachment of the pericardial sac to the body wall; apt. bstn, aperture of the branchiosternal canal into the abdominosternal chamber (cut); bstn. can, branchiosternal canal (cut); cap, posterior sclerotized cap of pericardial sac; gut, gutter in lateral walls of the thoracic endopleurites; p5, 5th pereiopod (cut); per, pericardial sac; th. som, 8 th thoracic somite.

\section{Water flow patterns in the branchial chambers}

The edges of the branchiostegites fit very closely to the bases of the chelipeds and the other pereiopods and there are no functional Milne-Edwards' openings in these regions. Water enters the branchial chambers at the base of the 3rd maxillipeds beneath the scaphognathite chambers (Fig. 1). Dye tracer studies showed that leakage of water from the setae-lined edges of the various structures making up the inhalant and exhalant canals was minimal and that there was no mixing of the two streams. In the hypobranchial chamber water flows backwards under the lateral endopleural shelf and passes into the epibranchial chamber between the gill lamellae. The gutter in the walls of the endopleurites possibly serves to guide water posteriorly to the very end of the branchial chamber. There are no dead spaces such as have been reported in Carcinus by Arudpragasam \& Naylor (1964) and Hughes et al. (1969). In the epibranchial chamber water flows anteriorly and is pumped out through the exhalant canal (Fig. 1). 
Ventilation of the abdominosternal chamber

In adult female crabs which are actively ventilating their branchial chambers, dye solution introduced in the vicinity of the telson is sucked into the abdominosternal chamber via the telson notch when the telson is extended and is expelled through the exhalant respiratory opening. When the telson is firmly pressed in against the sternum no water passes into the abdominosternal chamber either via the telson region, or from around the rim of the abdomen.

Dye solution will enter via holes bored in the abdominal wall of the abdominosternal chamber but never flows out in the reverse direction. Holes were bored in that region of the abdomen of living crabs immediately below the openings of the branchiosternal canals such that these canals could be observed during ventilation of the abdominosternal chamber. Dye solution introduced at the entrance of these holes was immediately sucked into the abdominosternal chamber irrespective of whether the telson was extended or not. From here the dye solution passed into the branchial chambers via the branchiosternal canals. The valves plugging the canals hinged upwards (i.e. towards the branchial chamber) and water flowed in around them. Water only flowed from the abdominosternal chamber into the branchial chambers when the scaphognathites were beating; when the scaphognathites stopped, the valves hinged downwards and plugged the branchiosternal canals. No water passed from the branchial chambers into the abdominosternal chamber except for a very small amount while the valves were closing.

In the branchial chambers water entering from the abdominosternal chamber joins the water stream in the posterior hypobranchial chamber and passes into the epibranchial chamber and out via the exhalant canal. During abdominosternal chamber ventilation the pleopods are rocked to-and-fro, completely mixing the water.

These observations suggest that the telson and pericardial sacs act as one-way valves. The telson valve is under obvious nervous control but the action of the pericardial valves is probably automatic. If the telson is extended while the scaphognathites are beating, the considerable negative pressure in the branchial chambers $(\sim 1 \mathrm{~cm}$ of water; Schembri, 1979) causes the flexible pericardial valves to be sucked upwards and hence to open. Water is pumped into the abdominosternal chamber which is now confluent with the branchial chambers and thus also under negative pressure (Fig. 8(b)). When the telson valve is shut, the pericardial valves once again plug the branchiosternal canals (Fig. 8(a)).

The return of the pericardial valves is probably due partly to their natural elasticity. If the pericardial valves of dead fixed crabs are pushed open with a fine needle, they then return to their original position, though not very quickly. It may also be due in part to the positive pressure of the fluid in the lumen of the pericardial cavity with which they are confluent. Blatchford (1971) has found that in Carcinus a relatively high positive pressure of $11-12 \mathrm{~cm}$ of water is maintained in the dorsal pericardial cavity. The pressure in the lateral pericardial cavities changes from just above ambient to negative $(-1 \mathrm{~cm}$ of water) during systole. It is not clear to which pericardial cavity the lumen of the pericardial sacs of E. tuberosa are connected. However, the fluid in the lumen is clearly under pressure since the posterior sclerotized cap of the sacs is stretched taut and could be seen to vibrate with each heart beat.

Simultaneous recordings of the hydrostatic pressure changes in the branchial and abdominosternal chambers of Ebalia support this mechanism. During ventilation of the branchial chambers, the pressure in these is negative, but is zero (ambient) in the 


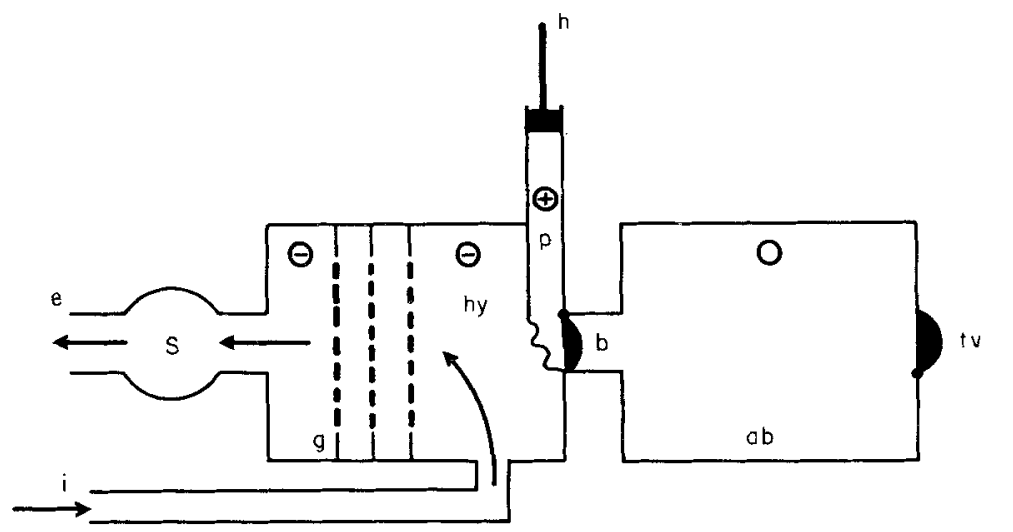

(a)

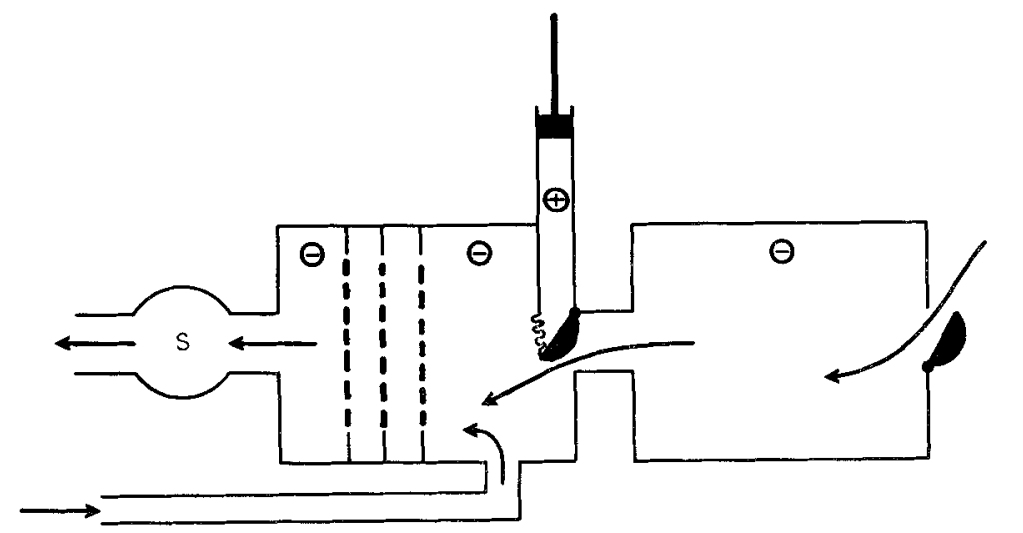

(b)

Fig. 8. Diagrammatic representation of branchial and abdominosternal chamber ventilation in adult female E. tuberosa; (a) telson valve closed, branchial chamber ventilated only; (b) telson valve open, abdominosternal chamber ventilated. $(+)$, positive pressure; $(-)$, negative pressure; 0 , "zero" pressure (ambient). Arrows show path of water flow. Key: ab, abdominosternal chamber; b, branchiosternal canal; e, exhalant channel; g, gills; $h$, heart; hy, hypobranchial chamber; $i$, inhalant channel; $p$, pericardial sacs; $S$, scaphognathites; $t v$, telson valve.

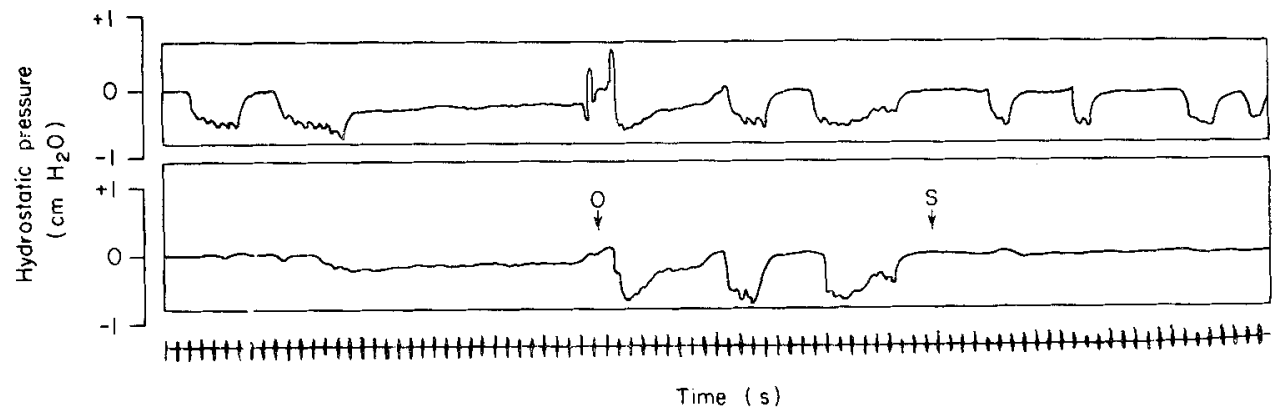

(a)

FIG. 9. Simultaneous recordings of hydrostatic pressure changes in (a) the branchial chamber, and (b) the abdominosternal chamber of an adult female $E$. tuberosa buried in the substratum. Note the correlation between the two traces when the telson valve is open. $O$, telson valve open; $S$, telson valve shut. 
abdominosternal chamber when the telson is closed. When the telson is open, pressure in the abdominosternal chamber drops to a value similar to that in the branchial chamber and the pressure trace obtained from these two chambers is identical until the telson valve shuts (Fig. 9).

\section{Discussion}

In E. tuberosa ingress of sediment into the branchial chambers is prevented by not having functional inhalant respiratory openings at the bases of the pereiopods. Instead, water passes into the branchial chambers via the inhalant canals formed partly by some of the buccal appendages and partly by the wall of the buccal frame. This is but one of the many morphological adaptations evolved by brachyurans to prevent clogging of the gills with sediment when buried in the substratum. Others include the antennal tubes and reversed direction of water flow in the branchial chambers of Corystes (Arudpragasam \& Naylor, 1966; Hartnoll, 1972; Bridges, 1979) and Atelecyclus (Bridges, 1976); the reversed direction of the respiratory current in buried Ovalipes (Caine, 1974); and the inhalant channels formed by apposition of the inner faces of the folded chelae against the pterygostomial regions of the carapace in burrowing portunids and calappids (Schäfer, 1954; Glaessner, 1969; Warner, 1977).

In those species where the functional morphology of the respiratory and associated structures has been studied, the setae lining these structures have been found to play important roles. E. tuberosa is no exception, the setation of the respiratory structures having several functions: (i) the appendages forming the inhalant and exhalant canals are held together by a series of flanges and interlocking setae which ensure that the two water flows are kept separate; (ii) the setae lining the edges of the abdomen, sternum, telson, 3rd maxillipeds and buccal frame form screens which prevent sediment from penetrating and fouling the underlying structures; these include the egg-mass in incubating females; (iii) the setae lining the scaphognathites serve to increase the surface area of these appendages and also to act as gaskets; (iv) specialized setae on the base and mastigobranch of the epipodites of the 1st maxillipeds clean the scaphognathites and outer surface of the gills.

The morphology of the setae is correlated with their function: those setae which lock appendages together, form screens, extend surfaces or act as gaskets are all feathery plumose or pappose types, while cleaning setae bear long setules and denticulations and act as rakes or brushes.

Very few observations have been made on how ovigerous female crabs which bury themselves in the sediment manage to ventilate the egg-mass without fouling it. In buried, ovigerous female Corystes, a portion of the exhalant water which emerges adjacent to the base of the last pair of pereiopods flows through and around the eggs (Hartnoll, 1972). In other species, berried females perhaps do not bury while incubating.

In nearly all leucosiids the eggs are completely enclosed in the abdominosternal chamber during the incubation period. In E. tuberosa, water can only enter this chamber anteriorly through the telson region, the remaining edges being practically water-tight. The branchiosternal canals connecting the abdominosternal chamber to the branchial chambers in $E$. tuberosa were first described by Drach (1955). Drach interpreted the modified pericardial sacs as functioning like pistons in the branchiosternal canals, actively pumping 
water from the branchial chambers into the abdominosternal chamber and out via the telson valve. On theoretical grounds such a mechanism is unlikely since it implies two pumps at opposite ends of the branchial chamber (the scaphognathite anteriorly and the pericardial "pump" posteriorly) working in opposition. The modified pericardial sacs of Ebalia are automatic one-way valves which open when the telson valve opens and shut when the telson valve shuts (Fig. 8).

The normal function of the pericardial sacs in brachyurans appears to be to accommodate an increasing haemolymph volume as water enters the crab during proecdysis, and then to expand and contract slightly during ecdysis to facilitate shedding of the old carapace (Otto, 1937; Drach, 1939; Bliss, 1963; Rao, 1968; Mason, 1970). In addition, the setae and convoluted surfaces of the enlarged pericardial sacs of some terrestrial crabs serve to transfer water from the substratum to the branchial chambers by capillarity (Bliss, 1963; Mason, 1970). In E. tuberosa, the pericardial sacs probably function in the same way as in other crabs during moulting. Following the pubertal/terminal moult in females (Schembri, 1980), however, the pericardial sacs become modified as valves. This specialized function of the pericardial sacs appears to be restricted to the Leucosiidae.

$E$. tuberosa burrows in the substratum to the level of the eyes leaving the inhalant and exhalant openings in contact with the overlying water (Schembri, 1979). The telson is so situated just under the endopodites of the 3rd maxillipeds (Fig. 1) that when the telson valve is opened, water is sucked in at the distal ends of the 3rd maxillipeds at the surface of the sediment, down between the inner surface of the 3rd maxillipeds and the outer surface of the 2nd maxillipeds and into the abdominosternal chamber, ventilating the egg-mass.

I am grateful to Professor J. A. Allen for his interest in this work and for providing the necessary facilities. I thank Professor B. E. Leake and Dr M. C. Keen of the Department of Geology, University of Glasgow for use of the SEM. Thanks are due also to Dr A. C. Taylor for the loan of equipment and for his help and advice. The work was carried out under tenure of a Commonwealth Scholarship awarded by the Association of Commonwealth Universities.

\section{REFERENCES}

Arudpragasam, K. D. \& Naylor, E. (1964). Gill ventilation and the role of reversed respiratory currents in Carcinus maenas (L.). J. exp. Biol. 41: 299-307.

Arudpragasam, K. D. \& Naylor, E. (1966). Patterns of gill ventilation in some decapod Crustacea. J. Zool., Lond. 150: $401-411$.

Atkinson, R. J. A. (1971). Aspects of the behavioural physiology and ecology of some decapod crustaceans. Ph.D. thesis, University College, Swansea.

Balss, H. (1940). Decapoda. Bronn's Tierreichs 5 part 1: Crustacea, Book 7: 1-160.

Balss, H. (1957). Systematik. Bronn's Tierreichs. 5 part 1: Crustacea, Book 7 Decapoda: 1505-1770.

Blachford, J. G. (1971). Haemodynamics of Carcinus maenas (L.). Comp. Biochem. Physiol. 39A: 193-202.

Bliss, D. E. (1963). The pericardial sacs of terrestrial Brachyura. In Phylogeny and evolution of Crustacea: $59-78$. Whittington, H. B. \& Rolfe, W. D. I. (Eds). [Spec. Publs Mus. comp. Zool.]. Massachusetts: Harvard University Press.

Bridges, C. R. (1976). A study of the respiratory physiology of Galathea strigosa (L.) and Corystes cassivelaunus (Pennant). Ph.D. thesis, University of Liverpool.

Bridges, C. R. (1979). Adaptations of Corystes cassivelaunus to an arenicolous mode of life. In Cyclic phenomena in marine plants and animals: 317-324, Naylor, E. \& Hartnoll, R. G. (Eds). Oxford: Pergamon Press. 
Caine, E. A. (1974). Feeding of Ovalipes guadulpensis (Saussure) (Decapoda: Brachyura: Portunidae), and morphological adaprations to a burrowing existence. Biol. Bull. mar. biol. Lab. Woods Hole 147: 550-559.

Cuénot, L. (1891). Études sur le sang et les glandes lymphatiques dans la série animale. II. Invertébrés. Archs Zool. exp. gén. (2) 9: 13-90.

Cuénot, L. (1893). Études physiologiques sur les Crustacés Décapodes. Archs Biol., Paris 13: 245-303.

Drach, P. (1939). Mue et cycle d'intermue chez les Crustacés Décapodes. Annls Inst. océanogr. Paris 19: 103-391.

Drach, P. (1955). Les Leucosiidés et la réalisation d'une fonction nouvelle chez les Crustacés Décapodes. C. $r$. hebd. Séanc. Acad. Sci., Paris 241: 1998-2001.

Factor, J. R. (1978). Morphology of the mouthparts of larval lobsters, Humarus americanus (Decapoda: Nephropidae), with special emphasis on their setae. Biol. Bull. mar. biol. Lab. Woods Hole 154: 383-408.

Glaessner, M. F. (1969). Decapoda. In Treatise on invertebrate palaeontology. Part R: Arthropoda 4, 2: 400-532. Moore, R. C. (Ed.). Colorado: The Geological Society of America.

Hartnoll, R. G. (1972). The biology of the burrowing crab, Corystes cassivelaunus. Bijdr. Dierk. 42: 139-155.

Hughes, G. M., Knights, B. \& Scammell, C. A. (1969). The distribution of $P_{\mathrm{O}_{2}}$ and hydrostatic pressure changes within the branchial chambers in relation to gill ventilation of the shore crab Carcinus maenas L. J. exp. Biol. 51: 203-220.

Mason, C. A. (1970). Function of the pericardial sacs during the moult cycle in the land crab Gecarcinus lateralis. J. exp. Zool. 174: 381-390.

Otto, J. P. (1937). Über die physiologische Deutung der Ausstülpungen des Perikards bei Krabben und die Dehnbarkeit der gepanzerten Tiere bei Erhökung des mechanischen Innendrucks. Zool. Anz. 117: 215-220.

Pearson, J. (1908). Cancer. L.M.B.C. Mem. typ. Br. mar. Pl. Anim. No. 16: 1-209.

Pilkington, J. B. \& Simmers, A. J. (1973). An analysis of bailer movements responsible for gill ventilation in the crab, Cancer novaezelandiae. Mar. Behav. Physiol. 2: 73-95.

Rao, K. R. (1968). The pericardial sacs of Ocypode in relation to the conservation of water, molting, and behavior. Am. Zool. 8: 561-567.

Scammell, C. A. (1971). Respiration and its nervous control in the shore crab, Carcinus maenas (L.) including a comparative study of the functional respiratory morphology in decapod crustaceans. Ph.D. thesis, University of Bristol.

Schäfer, W. (1954). Form und Funktion der Brachyuren-Schere. Abh. senckenb. naturf. Ges. No. 489: 1-65.

Schembri, P. J. (1979). An unusual respiratory rhythm in the crab Ebalia tuberosa (Pennant) (Crustacea: Decapoda: Leucosiidae). In Cyclic phenomena in marine plants and animals: 327-335. Naylor, E. \& Hartnoll, R. G. (Eds). Oxford: Pergamon Press.

Schembri, P. J. (1980). Aspects of the biology, behaviour and functional morphology of the crab Ebalia tuberosa (Pennant). Ph.D. thesis, University of Glasgow.

Warner, G. F. (1977). The biology of crabs. London: Elek Science. 